\title{
HPV vaccination among ethnic minorities in the UK: knowledge, acceptability and attitudes
}

\author{
LAV Marlow, \\ 'Department of Epidemiology and Public Health, Cancer Research UK Health Behaviour Research Centre, UCL, Gower Street, London WCIE 6BT, UK
}

BACKGROUND: Human papillomavirus (HPV) vaccination offers a unique opportunity for the primary prevention of cervical cancer. Studies suggest that knowledge and attitudes about the vaccine are likely to influence uptake. One limitation of most studies assessing HPV vaccine knowledge, attitudes and acceptability is their under representation of ethnic minorities. It is important to ensure that our understanding of HPV knowledge and attitudes include all ethnic groups in the UK. This article reviews research that has considered knowledge, acceptability and attitudes about HPV and the HPV vaccine among ethnic minorities in the UK.

Methods: Articles in Medline, CINAHL and PsycINFO (January 2000-March 20I0) were searched.

RESULTS: A total of 17 UK-based papers examined knowledge, attitudes or acceptability related to HPV vaccination in the 'lay' population (parents, adolescents or the general population as opposed to health professionals) and reported findings by ethnicity. CONCLUSION: Findings seem to suggest lower awareness of HPV and lower acceptability of the vaccination, which could be important if they are reflected in uptake. More research is needed with ethnic minority groups, particularly in the context of the vaccination programme.

British Journal of Cancer (20II) 1 05, 486 - 492. doi:10.1038/bjc.20II.272 www.bjcancer.com

(c) 20II Cancer Research UK

Keywords: review; ethnic; vaccination; cervical cancer; knowledge

\section{INTRODUCTION}

Each year the UK sees around 3000 new cases of cervical cancer and just under 1000 deaths (CRUK, 2007, 2008). Incidence of cervical cancer has been dramatically reduced by the cervical screening programme, which is estimated to save around 3000 lives a year (Peto et al, 2004). However, there are inequalities in cervical cancer, with higher rates in women from deprived backgrounds (Quinn et al, 2001; Coupland et al, 2007). Until recently no research had considered ethnic inequalities, but a report published by the National Cancer Intelligence Network in 2009 suggested that Asian and Black women over 65 years are at increased risk of cervical cancer, whereas Asian women under 65 have a lower incidence of the disease. Small numbers meant it was not possible to explore ethnic variation in mortality rates (NCIN, 2009). Differences in lifestyle, which lead to increased risk of human papillomavirus (HPV) exposure or persistence (e.g. number of sexual partners, smoking), or screening participation are thought to be the most likely reasons for inequalities in cervical cancer (Akers et al, 2007). In particular, research has suggested lower uptake of cervical screening among some ethnic groups (Webb et al, 2004) and a recent study found that this was the case even when controlling for a range of socioeconomic status (SES) variables (Moser et al, 2009).

In 2008, a national HPV vaccination programme was launched in the UK. The HPV vaccination offers protection against HPV types 16 and 18 , which are responsible for around $70 \%$ of cervical

*Correspondence: Dr LAV Marlow; E-mail: I.marlow@ucl.ac.uk Received 2 June 201 I; accepted 24 June 201 I cancer (Munoz et al, 2004). The vaccine is offered to all girls in school year 8 (12-13 years), as well as to all girls up to 18 years old as part of a catch-up campaign (until July 2011). In the majority of cases it is offered in schools but is sometimes offered through primary care. The HPV vaccination programme offers the potential to overcome inequalities in cervical cancer, but this relies on good uptake of the vaccination across all SES and ethnic groups. Overall uptake of all three doses of the vaccine for the first year of the immunisation programme in England (2008/2009) was $80 \%$ for $12-13$-year olds and $32 \%$ for $17-18$-year olds (Department of Health, 2010a), but coverage has not been reported separately for different ethnic or SES groups.

Despite the high uptake levels that are being reported, it is still important to consider the reasons why some adolescents do not get the HPV vaccination and the potential for inequalities in HPV vaccine uptake. There are many practical barriers that may stop adolescents from having HPV vaccination (e.g. absence from school, difficulties getting to the doctor's surgery), but beliefs and attitudes about vaccines are also likely to have an influence on the decision to accept a vaccine (Sturm et al, 2005). In addition good knowledge about HPV is important in order to ensure decisions about the vaccine are informed (Marteau et al, 2001). In the 5 years preceding its launch, several studies explored knowledge, attitudes and acceptability of HPV vaccination in the UK. Because most studies were carried out before the implementation of the vaccination programme their focus was on acceptability (intention to accept the vaccine) rather than uptake, but the findings have helped to establish an understanding of the socio-demographic and psychosocial factors, which may have a role in the decision to accept HPV vaccination. One limitation of these studies is their 
underrepresentation of ethnic minorities (i.e., those from nonwhite backgrounds). In 2001, 4.6 million people in the UK considered themselves to be from an ethnic group other than 'white' (ONS, 2004). This non-white population is made up of predominantly South Asian (from this point on South Asian will be referred to as Asian) (mostly Indian, Pakistani and Bangladeshi), Black (mostly Caribbean and African) and Chinese people, and people who consider themselves to be from mixed backgrounds. Across the UK, these groups account for just $8 \%$ of the population, but certain areas have much greater proportions than others (Dobbs et al, 2006).

The literature on uptake of childhood vaccinations suggests that uptake varies by ethnicity, with the highest rates among Asian parents, followed by White and Black parents (Baker et al, 1984; Hawker et al, 2007). When making the distinction between children who are partially vaccinated and those who are unvaccinated, it appears that partial vaccination is associated with living in disadvantaged and ethnically dense areas, whereas parents of unvaccinated children are more highly qualified and more likely to be from Black Caribbean backgrounds (Samad et al, 2006). In addition, it appears that the drop in MMR uptake, following its suggested link with autism, was less prominent in non-white parents (Hawker et al, 2007). These findings suggest that some minority groups have lower and some have higher uptake of childhood vaccinations. However, we cannot assume that HPV vaccination will be seen in the same way as other childhood vaccinations. The Cancer Reform Strategy highlights the importance of reducing ethnic inequalities in cancer awareness, attitudes and uptake of prevention services (Department of Health, 2007). It is therefore important to ensure that our understanding of knowledge, attitudes and acceptability of the HPV vaccination spans all ethnic groups in the UK and is not just limited to the white population. The aim of this paper is to review the findings of UK-based research that has considered these psychosocial issues in ethnic minority groups.

\section{MATERIALS AND METHODS}

Articles from January 2000 to March 2010 in Medline, CINAHL and PsycINFO were searched using the terms HPV; AND vaccine (or immunisation); AND attitude, aware, barrier, belief, knowledge, perception, psychol ${ }^{\star}$ or accept $^{\star}$. Reviews, editorials, dissertations, letters and books were excluded. Peer-reviewed journal articles were included if they presented original research, examined knowledge, attitudes or acceptability related to HPV vaccination in a lay population (studies of health professionals were excluded), were carried out in the UK and reported findings by ethnicity.

For the purpose of this review, ethnicity is defined as 'shared origins or social background; shared culture and traditions that are distinctive, maintained between generations, and lead to a sense of identity and group; and a common language or religious tradition' (pp 327, Senior and Bhopal, 1994). There are many difficulties with using ethnicity as a variable in epidemiological research and a major one of these is which measurement to use. In the UK Census in 2001, ethnicity was assessed by asking participants which ethnic group they perceived themselves to be in. This 'self-report' measure of ethnicity is considered to be an acceptable form of assessment. It allows participants to select different categories at two or more time points, which means it could have limited reliability, however, it is commonly used in research and for the purpose of this review we will consider papers that have measured ethnicity in this way.

There are also many other important ethnicity-related variables including current geographical location, language spoken at home, country of birth, number of years living in the UK and religion. In addition, non-white ethnic groups in the UK tend to be from lower social grades, have lower incomes and are more likely to live in deprived areas. Some minority groups also have lower educational qualifications, although this is not the case across all groups (Nazroo, 2006). Good research exploring ethnicity would therefore take into account a number of the related variables mentioned above. As many of the papers exploring HPV vaccine acceptability have not focused primarily on ethnicity we did not expect this to be the case, hence these variables were not set as part of the inclusion criteria for this review, however, where they have been considered the related findings will be discussed.

\section{RESULTS}

Worldwide 266 articles reported original research (qualitative or quantitative) that examined awareness, knowledge or attitudes related to HPV vaccines, but only 26 of these studies were carried out in the UK. Searching the references of these papers revealed another eight papers. Of the 34 UK-based papers identified 17 were in the 'lay' population (parents, adolescents or the general population as opposed to health professionals) and reported findings by ethnicity. Two of these papers were qualitative (Vallely et al, 2008; Marlow et al, 2009d) and 15 were quantitative (quantitative papers are summarised in Table 1).

\section{Knowledge about HPV}

Between 2001 and 2007, five studies looked at awareness of HPV in the UK (Pitts and Clarke, 2002; Philips et al, 2003; Waller et al, 2003, 2004; Marlow et al, 2007a). Findings pointed to very low levels of awareness with only around $30 \%$ of women saying that they had heard of the virus. There was a consistent socioeconomic gradient in HPV awareness, but the small number of non-white participants precluded conclusions about ethnic variation.

In 2007, a study of HPV knowledge recruited participants on the streets of Birmingham, an area with a high proportion of nonwhite residents (Walsh et al, 2008). Purposive sampling was used to ensure a good proportion of ethnic minority participants were included (25\% of the sample). Participants were asked six questions relating to their awareness of HPV (e.g. have you heard about HPV, did you know that the government is considering offering HPV vaccination to school girls aged 10-12) and were then allocated a score ranging from 0 (low knowledge) to 6 (high knowledge). Overall, knowledge was extremely poor, with $81 \%$ scoring the minimum (i.e. 0 ). This varied by ethnicity, with $92 \%$ of non-white participants scoring ' 0 ' compared with $77 \%$ of white participants, and this difference was significant even when controlling for gender, age and social class. Those who could not speak English fluently were unable to participate in the survey and this may have resulted in a more acculturated sample, hence true levels of knowledge in the non-white population may have been even lower. In a second Birmingham-based study, published as a short letter to the editor, adolescents aged 12-13 years and their parents were recruited through schools (Das et al, 2010). Mean scores on a knowledge scale were 4.54 for non-white and 4.94 for white participants (out of a possible 8). This difference was significant in adjusted analyses, although it is not clear what variables were adjusted for. This study was conducted after introduction of the vaccine, in the target population and the questions included aspects of HPV knowledge that it is important for this population to know e.g. 'does the vaccine protect against other sexually transmitted infections?' and 'is cervical screening necessary after vaccination is given?' However, because of the publication format there is little detail provided about the methodology, making it difficult to judge the quality of the study.

In another study, quota sampling was used to recruit women from the six main ethnic minority groups in the UK and a white comparison group (Marlow et al, 2009c). Interviews were carried 
Table I Summary of quantitative studies that have assessed ethnic differences in knowledge and acceptability of HPV vaccination in the UK

\begin{tabular}{lllll}
\hline & $\begin{array}{l}\text { Study design } \\
\text { (participants) }\end{array}$ & $\begin{array}{l}\text { Ethnic breakdown } \\
\text { of sample }\end{array}$ & Outcomes & $\begin{array}{l}\text { Main ethnicity-related } \\
\text { findings }\end{array}$
\end{tabular}

White (66\%), Indian (13\%), Black Acceptability for daughter African (9\%), Black Caribbean (single item).

(8\%), others (4\%)

Brabin et al, (2007) School-based survey, adjusted for sampling (parents, $n=317$, $\mathrm{RR}=22 \%)$.

White (66\%), Indian (13\%), Black to vaccinating a well$(8 \%)$, others (4\%)

\section{informed child against HPV}

without parental consent (qualitative responses coded as positive, less positive or other).
Marlow et al (2007a) A nationally representative sample $(n=1620, R R=53 \%)$.

Marlow et al (2007b) School-based survey (parents, $n=684,57 \%$ )

White (94\%), Non-white (6\%). daughter $<16$ years, within a nationally representative sample $(n=296, R R=53 \%)$

Brabin et al (2008) Vaccine feasibility study in two PCTs in Manchester $(n=2817)$

School-based data on ethnic proportion in each school.

White (90\%), Non-white (10\%).
White (94\%), Non-white (6\%).

Awareness of HPV (single prompted item)

Acceptability for daughter (single item).

Most acceptable age for vaccination (single item)

Acceptability of HPV vaccination (single item)

Uptake of the first two doses of the vaccine.

Knowledge (6-point knowledge score).

Attitudes (single item: do you think that the introduction of HPV vaccination is a good idea?).

White (73\%), Asian (13\%), Bla (men and women, $n=420$ ).
Ethnicity and religion were not associated with acceptability.

White and Black Caribbean parents were more supportive of vaccinating without parental consent than Black African or Indian parents. Religion was not associated with attitude to consent.

Ethnicity was not associated with awareness of HPV.

Ethnicity was not associated with acceptability. Those

from 'other' religions were less accepting. Ethnicity and religion were associated with selecting an older age for HPV vaccination.

Ethnicity was not associated with acceptability.

Uptake was lower in schools that had higher proportions of ethnic minorities and those eligible for free school meals.

Non-white participants were more likely to score 0 .

Non-white participants

showed less positive attitudes to HPV vaccination.

Multivariate analyses

The effect of ethnicity on acceptable age for HPV accination disappeared when controlling for other factors. Religion remained significant.

Ethnic differences in knowledge remained when controlling for gender, age and social class.

Ethnic differences in attitudes remained when controlling for age (SES was not associated with attitudes, so not controlled for).

Having consented or refused HPV There was no association vaccination for their daughter. between ethnicity and consenting/refusing the HPV vaccination, However, nonwhite parents were less likely to have returned the questionnaire.

Marlow et al (2009a) A sub-set of mothers from a

Mothers: White (9|\%), Black nationally representative sample (4\%), Asian (4\%). who had a daughter under 16 school-based study of $16-18$ year-old girls $(n=328)$
Anticipated risk compensation (sum of two items relating to more sex or unprotected sex following HPV vaccination), girls also completed questions relating to their own behaviour.

Awareness of HPV (have you Indian (25\%). White (21\%) Face-to face interviews, quota
sampling (women only, $n=950$ $\mathrm{RR}=70 \%)$.
Pakistani (17\%), Caribbean (14\%), heard of HPV?).

African (I /\%), Bangladeshi (7\%), Acceptability for a daughter Chinese (6\%).
Compared with white participants, Black and Asian mothers and girls from Black backgrounds had higher risk compensation scores. Among girls there was no association between ethnicity and belief about changes in own sexual behaviour. had heard of HPV. Religion, were also associated with acceptability.

White (58\%), Asian ( I3\%), Black Acceptability of HPV vaccination (25\%), other (4\%).

\footnotetext{
(16-18-year olds, $n=328)$.

Marlow et al (2009b) School-based survey
}

Ethnic minority participants were less likely to say they migration status and language awareness.

Ethnic minority participants were less likely to say they would accept HPV vaccination. Religion, migration status and language were also associated with
Students from Asian

backgrounds were less likely to say they would accept HPV vaccination. Religion an language spoken at home were also associated with acceptability. multivariate analyses ethnicity and religion remained significant of HPV awareness.

For HPV vaccine acceptability, ethnicity and religion were significant in multivariate analyses, which included

SEC and the other ethnicity related variables.

In multivariate analyses with ethnicity, religion and anguage spoken at home, only religion was significant. 
Table I (Continued)

\begin{tabular}{|c|c|c|c|c|c|}
\hline Study & $\begin{array}{l}\text { Study design } \\
\text { (participants) }\end{array}$ & $\begin{array}{l}\text { Ethnic breakdown } \\
\text { of sample }\end{array}$ & Outcomes & $\begin{array}{l}\text { Main ethnicity-related } \\
\text { findings }\end{array}$ & Multivariate analyses \\
\hline Das et al (20।0) & $\begin{array}{l}\text { School-based survey } \\
(12-13 \text {-year olds and their } \\
\text { parents, } n=434) \text {. }\end{array}$ & $\begin{array}{l}\text { White }(72 \%) \text {, Asian ( } 18 \%) \text {, Mixed } \\
(6 \%) \text {, Black (3\%), other (1\%). }\end{array}$ & $\begin{array}{l}\text { Knowledge (8-point knowledge } \\
\text { score). }\end{array}$ & $\begin{array}{l}\text { Mean knowledge scores } \\
\text { were lower for non-white } \\
\text { participants. }\end{array}$ & \\
\hline Forster et al (20।0b) & $\begin{array}{l}\text { School-based } \\
(16-18 \text {-year olds, } \\
n=617,94 \%)\end{array}$ & $\begin{array}{l}\text { White (55\%), Asian (I9\%), Black } \\
\text { (I2\%), other (I I\%). }\end{array}$ & $\begin{array}{l}\text { Acceptability of HPV vaccine } \\
\text { (sum of two items). }\end{array}$ & $\begin{array}{l}\text { Ethnicity and religion were } \\
\text { associated with acceptability. }\end{array}$ & \\
\hline Forster et al (20।0a) & $\begin{array}{l}\text { School-based (14-15-year olds, } \\
n=173) \text {. }\end{array}$ & $\begin{array}{l}\text { White (73\%), Asian (I I\%), other } \\
\text { (1 I\%), non-response (6\%). }\end{array}$ & $\begin{array}{l}\text { Intention to receive HPV } \\
\text { vaccination (single item). }\end{array}$ & $\begin{array}{l}\text { Neither ethnicity nor religion } \\
\text { was associated with intention } \\
\text { to receive HPV vaccination. }\end{array}$ & \\
\hline Roberts et al (201 I) & $\begin{array}{l}\text { Vaccine feasibility study in two } \\
\text { PCTs in Manchester }(n=2817) \text {. }\end{array}$ & $\begin{array}{l}\text { White }(9 \mid \%) \text {, Asian (5\%), Black } \\
(1 \%), \text { mixed (3\%), other (1\%). }\end{array}$ & $\begin{array}{l}\text { Three groups: uptake of all three } \\
\text { doses of the vaccine, active refusal } \\
\text { or non-response. }\end{array}$ & $\begin{array}{l}\text { Non-white girls were less } \\
\text { likely to be fully vaccinated } \\
\text { and more likely to be non- } \\
\text { responders. }\end{array}$ & $\begin{array}{l}\text { These effects remained when } \\
\text { controlling for deprivation } \\
\text { score. }\end{array}$ \\
\hline
\end{tabular}

Abbreviations: HPV = human papillomavirus; PCT = Primary Care Trust; RR = response rate, which is reported where possible.

Table 2 Studies that have looked at ethnic variation in parental acceptability of HPV vaccination

\begin{tabular}{llc}
\hline Study & Ethnic groupings (n) & Acceptability \% \\
\hline Brabin et al (2006) & White (207) & 81 \\
& Black Caribbean (25) & 56 \\
& Black African (28) & 71 \\
& Indian (39) & 67 \\
Marlow et al (2007a, b) & Others (13) & 85 \\
Walsh et al (2008) ${ }^{\text {a }}$ & White (6I7) & 76 \\
Marlow et al (2008) & Non-white (42) & 64 \\
Marlow et al (2009a, b, c, d) ${ }^{\text {a }}$ & White (305) & 91 \\
& Non-white (I I5) & 81 \\
& White (269) & 76 \\
& White British (I49) & 61 \\
& Pakistani (II2) & 63 \\
& Bangladeshi (45) & 11 \\
& Indian (130) & 18 \\
& Chinese (30) & 25 \\
& Caribbean (74) & 40 \\
& African (6I) & 49
\end{tabular}

Abbreviation: HPV = human papillomavirus. ${ }^{a}$ Mean significant differences were found.

out by multilingual interviewers in the language that women spoke at home. Women were asked 'before this interview, had you heard of HPV?' Awareness of HPV was lower in all ethnic minority groups: White (39\%), Chinese (18\%), Caribbean (14\%), Pakistani (12\%), Indian (9\%), African (8\%) and Bangladeshi (6\%). Religion, migration to the UK and language spoken at home were also considered in this study and each of these variables was a significant predictor of HPV awareness in univariate analyses, but in a multivariate analysis, only ethnicity and religion remained significant. However, the study used quota sampling, hence caution must be exercised when generalising the findings to the wider ethnic minority population.

\section{Acceptability of HPV vaccination}

Seven studies have quantitatively assessed parental acceptability of HPV vaccination in the UK and all suggest that around $74-88 \%$ of parents say they would accept HPV vaccination for their daughter (Brabin et al, 2006; Marlow et al, 2007b, 2008, 2009c; de Visser and McDonnell, 2008; Walsh et al, 2008; Morison et al, 2010). Findings in relation to ethnic minorities are limited and have been summarised in Table 2.

In 2006/2007 two school-based surveys assessed whether parents thought they would accept HPV vaccination for their daughter
(Brabin et al, 2006; Marlow et al, 2007b). Although there were slightly lower levels of HPV vaccine acceptability for ethnic minorities in both of these studies, the differences were not significant, perhaps because of the small numbers of non-white participants. However, in one of these studies the most acceptable age for HPV vaccination was also considered as an outcome and being from a non-white ethnic group was associated with a higher acceptable age. In multivariate analyses controlling for a range of demographic and attitudinal factors including religion, ethnicity was no longer a significant predictor of acceptable age of vaccination (Marlow et al, 2007b). The SES was not associated with acceptability in either of these studies.

In a subset of mothers within a nationally representative survey of British women, there was a $15 \%$ difference in the proportion of those who would accept HPV vaccination, between white $(76 \%)$ and non-white participants $(61 \%)$, but this finding was not significant, probably due to lack of power (Marlow et al, 2008). A study by the same authors that collected data using quota sampling to ensure adequate representation of each UK ethnic minority group, found that although $63 \%$ of white mothers said they would accept HPV vaccination, this was much lower among all ethnic minority mothers $(11-51 \%)$, with the lowest levels in South Asian mothers (11-24\%) (Marlow et al, 2009c). With more adequate sample sizes these differences were significant but as noted earlier, the quota sampling method makes generalisability to the wider population problematic. Acceptability also varied on the basis of migration status, language spoken at home and religion. In multivariate analyses, which included these variables and a measure of SES, only ethnicity and religion remained significant. Finally, a Birmingham-based street survey asked the more general question: 'do you think that the introduction of HPV vaccination is a good idea?' A significant ethnicity effect was found, with white participants showing more positive attitudes about HPV vaccination than non-white participants, (Walsh et al, 2008) but the same caveats associated with purposive sampling noted earlier apply.

Two studies have looked at HPV vaccine acceptability in young women aged 16-18 years (the age who were offered the vaccine as part of the catch-up programme) recruited though further education colleges in South East England - both found significant ethnic differences. In the first study, Asian students were less likely to say they would accept HPV vaccination than white students (83 versus 93\%), although in multivariate analysis adjusting for religion and language this effect disappeared (Marlow et al, $2009 \mathrm{~b}$ ). In a second study using mean intention as the outcome (based on the sum of two intention items), white students had higher intentions to receive the HPV vaccine than those from Asian, Black or other ethnic backgrounds (6.5 vs 5.9, 5.7 and 5.6 respectively). Religion was also associated with intention to receive 
the vaccine, but multivariate analyses were not carried out (Forster et al, 2010b). In another study, this time of 14-15-year olds, there were no ethnic differences in intention to accept HPV vaccination (Forster et al, 2010a).

All the above studies used acceptability (intention) as their outcome and there is little data on actual HPV vaccination uptake. However, several reports have been published from a feasibility study carried out in two Primary Care Trusts in Manchester in 2007-2008 (Brabin et al, 2008, 2009; Stretch et al, 2008; Roberts et al, 2011). This is the only study in the UK to consider actual uptake of HPV vaccination. Uptake of the first two doses of the vaccine was $69 \%$, but this figure was lower in schools that had a high proportion of ethnic minority children or of children eligible for free school meals (Brabin et al, 2008). Overall, 68\% of girls received all three doses of the vaccine, but non-white girls were less likely to be fully vaccinated than white girls (odds ratio $=0.67$, 95\% confidence interval: $0.49-0.92$ ) and non-response was more common in the non-white group (odds ratio $=1.80$, confidence interval: 1.27-2.55). These findings remained when controlling for socioeconomic deprivation. However, a large proportion of the ethnicity data was missing from the sample and had to be imputed (Roberts et al, 2011).

\section{Attitudes to HPV vaccination}

Box 1 summarises research findings in relation to HPV vaccine attitudes. Two early qualitative studies explored attitudes to HPV vaccination among white British parents (Noakes et al, 2006; Waller et al, 2006). The findings suggested that some general concerns about vaccinations, including safety worries and trust in those recommending vaccinations, might be important predictors of HPV vaccine acceptability. In addition, some more specific concerns about HPV vaccination included the sexually transmitted nature of the virus, which some parents felt may give girls carte blanche for risky sexual behaviour. A third study used similar qualitative methods, but with purposive sampling to recruit mothers from Black/Black British and Asian/Asian British backgrounds (Marlow et al, 2009d). Many of the concerns raised appeared to be consistent with the previous groups of white British parents (e.g. concerns about safety), but there were some additional issues. Mothers seemed to have stronger views about the age of HPV vaccination and this was mainly due to religious beliefs about the unacceptability of sex outside of marriage. They felt that the vaccination would not be necessary for their daughters at $12-13$ years and some felt it would not be necessary at all. This is consistent with the quantitative study mentioned earlier that showed mothers from non-white backgrounds had a preference for vaccination against HPV at an older age (Marlow et al, 2007b). Mothers also felt the 'taboo' surrounding sexually transmitted infections would make it difficult to discuss the vaccination with relatives, and this was something, which they felt was usually an important part of the vaccine decision-making process.

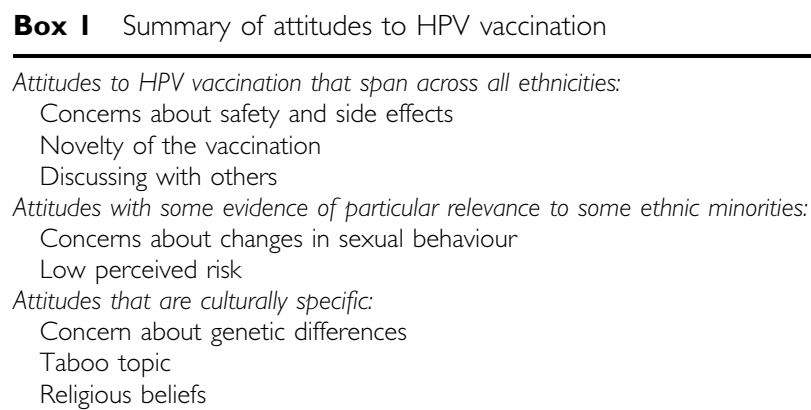

In one quantitative survey that included mothers from a range of ethnic minority groups, reasons were given for intended acceptance of HPV vaccination (Marlow et al, 2009c). 'Protection' offered by the vaccine was cited less often among Indian (16\%), Pakistani (11\%), Bangladeshi (13\%) and Caribbean mothers (14\%) compared with white mothers (29\%). Needing more information to make a decision was cited more by Bangladeshi mothers than white British mothers (44\% compared with 16\%). Sex-related reasons (e.g. 'it encourages promiscuity') were more likely to be cited by Indian (15\%), Pakistani $(20 \%)$ and Caribbean mothers (16\%) compared with white British mothers (2\%). This finding is consistent with another study showing that the belief that HPV vaccination would change sexual behaviour was held more among mothers and adolescents from non-white ethnic groups (Marlow et al, 2009a).

There is some evidence that fathers in ethnic minority families may have a more important role in deciding about HPV vaccination (Marlow et al, 2009c), with a decision shared by both parents most likely in Indian (61\%), Pakistani (57\%), Bangladeshi $(66 \%)$, African $(63 \%)$ and Caribbean groups (56\%) and least likely in Chinese (30\%) and white groups (36\%). In addition, one study showed that Asian parents were less accepting of letting girls request vaccination at a sexual health clinic without parental consent (Brabin et al, 2007).

\section{DISCUSSION}

Few studies have considered ethnic differences in knowledge, attitudes and acceptability of HPV vaccination in the UK. The studies that have been carried out are mostly small and use varied outcome measures, which makes it impossible to combine the findings. There does appear to be consistency across studies, with both knowledge of HPV and acceptability of HPV vaccine being lower for non-white ethnic groups, even if the small sample sizes means these findings are not always significant. Unfortunately categorising ethnicity in this way is far from adequate, and leaves an important question unanswered - for which particular ethnic groups are there inequalities that need to be addressed? Ethnicity researchers have argued for the importance of using meaningful ethnic categories in epidemiological research (e.g. Bhopal, 2006; Nazroo, 2006), but as most of the studies considered in this review did not explicitly aim to explore the role of ethnicity, it is not surprising that they were not designed to include samples large enough to define ethnic categories more appropriately.

Having small numbers of ethnic minority participants also makes it difficult to disentangle ethnicity from other related variables such as language spoken at home, migration status, religion and SES. Understanding whether any of these variables would explain ethnic differences in HPV knowledge and acceptability would offer more insight. Only a few of the studies exploring acceptability included other ethnicity-related variables as potential confounders. Where language spoken at home and migration status were included they did not remain significant in multivariate analyses. However, religion either remained alongside ethnicity or caused the ethnicity effect to disappear from the model, suggesting it has an important role (Marlow et al, 2007a, b, $2009 b, c)$. Interestingly SES did not appear to explain ethnic differences in HPV vaccine acceptability (Marlow et al, 2009c) or actual uptake (Roberts et al, 2011).

The majority of the work presented here uses acceptability rather than uptake as the outcome. The most recent uptake figures for England showed that overall $76 \%$ of eligible girls received all three doses of the vaccine in $2009 / 2010$, with uptake over $80 \%$ in many areas (Department of Health, 2010b). This appears to be the case in some areas that are known to have high proportions of ethnic minorities living there (e.g. London borough of Brent: $80 \%$ ), although not for others (London borough of Newham: 68\%). 
Although there is a box on the vaccine consent form for parents to indicate their ethnicity, these data have not been made available (and may be very incomplete), hence estimates of variation in uptake by ethnic group rely on school or area level data. The hope is that this paper will inspire the continuation of research in the actual vaccination context.

This review also considered studies exploring knowledge of and attitudes towards HPV and the vaccine. Although knowledge is not closely correlated with acceptability, it was included because of the implications it has for informed consent. Ensuring people are well informed before making a health-related decision is expected to result in better patient outcomes, and respects the need to consider ethical principles and potential litigation (Marteau et al, 2001). Only three studies considered knowledge of HPV by ethnicity, and their findings suggested lower awareness of HPV and lower knowledge scores based on a range of relevant items (Walsh et al, 2008; Marlow et al, 2009c; Das et al, 2010). It is well established that attitudes are correlated with vaccine uptake, however, very few studies have considered attitudes towards HPV vaccination among ethnic minorities in the UK.

There is a need for more research that aims to explore HPV knowledge, attitudes and vaccination uptake among ethnic minorities, in the context of the actual vaccination programme. Future studies in this context will need to consider their methodology carefully. In order to make comparisons across a range of ethnic groups, very large samples of each group are needed. Quota sampling helps to overcome this problem, and was used in two of the studies described above (Walsh et al, 2008; Marlow et al, 2009c), but there are limitations to this method, with participants likely to be self-selected and not necessarily representative of the minority population. Using data from the HPV immunisation programme could overcome this bias and would ensure a large sample. One study in the Netherlands used this method, evaluating determinants of HPV vaccine uptake nationwide. Ethnic minority groups (recorded as parent's country of birth) only represented a small proportion of the sample, but the large sample size (384 869) meant they were able to look at ethnic differences and control for possible confounders (Rondy et al, 2010). Unfortunately ethnicity data is often missing from such records (Rondy et al, only had ethnicity data for $28 \%$ of adolescents). This means only smaller sub-samples can be included in analyses or ethnic data have to be imputed (as in Roberts et al, 2011). Another option is to recruit in the same way as a nationally population representative survey (i.e. by using lists such as the Postcode Address File) but to use 'ethnic boosts,' oversampling areas that have high proportions of ethnic minorities. This method is used in surveys such as the Health Survey for England, but is a very expensive method of data collection. Alternatively researchers may wish to focus their work on one or two ethnic groups.

\section{CONCLUSION}

We know relatively little about attitudes to HPV vaccination in ethnic minorities in the UK. Findings seem to suggest lower awareness of HPV and lower acceptability of the vaccination, which could be important if they are reflected in uptake. Only two studies have focused specifically on ethnic minorities in the UK (Marlow et al, 2009c, d), and the others have looked at ethnicity as just one of many factors. It is important to include ethnic minorities in cancer prevention research to ensure that culturally specific barriers are identified and potential ethnic inequalities are addressed. More research is needed, particularly in the context of the vaccination programme. Uptake figures so far suggest that the vaccine is generally well received, but details of ethnic variation in these figures are still being awaited.

\section{REFERENCES}

Akers AY, Newmann SJ, Smith JS (2007) Factors underlying disparities in cervical cancer incidence, screening, and treatment in the United States. Curr Probl Cancer 31: 157-181

Baker MR, Bandaranayake R, Schweiger MS (1984) Differences in rate of uptake of immunisation among ethnic groups. BMJ 288: $1075-1078$

Bhopal R (2006) Race and ethnicity: responsible use from epidemiological and public health perspectives. J Law Med Ethics 34: 500-507

Brabin L, Roberts SA, Farzaneh F, Kitchener HC (2006) Future acceptance of adolescent human papillomavirus vaccination: A survey of parental attitudes. Vaccine 24: 3087-3094

Brabin L, Roberts SA, Kitchener HC (2007) A semi-qualitative study of attitudes to vaccinating adolescents against human papillomavirus without parental consent. BMC Public Health 7: 20

Brabin L, Roberts SA, Stretch R, Baxter D, Chambers G, Kitchener H, McCann R (2008) Uptake of first two doses of human papillomavirus vaccine by adolescent schoolgirls in Manchester: prospective cohort study. BMJ 336: 1058

Brabin L, Roberts SA, Stretch R, Baxter D, Elton P, Kitchener H, McCann R (2009) A survey of adolescent experiences of human papillomavirus vaccination in the Manchester study. Br J Cancer 101: 1502-1504

Coupland V, Davies E, Kang J, Maddams J, Mak V, Møller H, Sehgal A, Tataru D (2007) Cancer Inequalities in London 2000-2004. Thames Cancer Registry: London

CRUK (2007) Cervical cancer-UK incidence statistics. Available at http:// info.cancerresearchuk.org/cancerstats/types/cervix/incidence/index.htm (accessed 12 August 2010)

CRUK (2008) Cervical cancer-UK mortality statistics. Available at http:// info.cancerresearchuk.org/cancerstats/types/cervix/mortality/index.htm (accessed 12 August 2010)

Das A, Madhwapathi V, Davies P, Brown G, Dearnley E, Spencer A, Williams H (2010) Knowledge and acceptability of the HPV vaccine by school children and their parents in Birmingham. Vaccine 28: 1440 - 1446 de Visser R, McDonnell E (2008) Correlates of parents' reports of acceptability of human papilloma virus vaccination for their schoolaged children. Sex Health 5: $331-338$

Department of Health (2007) Cancer Reform Strategy. Available at http:// tinyurl.com/cancerreformstratergy (accessed 12 August 2010)

Department of Health (2010a) Annual HPV vaccine uptake in England: 2008/2009. Available at http://tinyurl.com/AnnualHPVuptakeEngland (accessed 12 August 2010)

Department of Health (2010b) Annual HPV vaccine uptake in England: 2009/2010. Available at http://tinyurl.com/AnnualHPVuptakeEngland2 (accessed 31 May 2011)

Dobbs J, Green H, Zealy L (2006) Focus on: Ethnicity and Religion. Palgrave Macmillan: Hampshire, UK

Forster AS, Marlow LA, Waller J (2010a) Adolescents' beliefs about their parents' human papillomavirus vaccination decisions. BJOG 117: 229-233

Forster AS, Marlow LA, Wardle J, Stephenson J, Waller J (2010b) Understanding adolescents' intentions to have the HPV vaccine. Vaccine 28: $1673-1676$

Hawker JI, Olowokure B, Wood AL, Wilson RC, Johnson R (2007) Widening inequalities in MMR vaccine uptake rates among ethnic groups in an urban area of the UK during a period of vaccine controversy (1994-2000). Vaccine 25: 7516-7519

Marlow LA, Waller J, Wardle J (2007a) Public awareness that HPV is a risk factor for cervical cancer. Br J Cancer 97: 691-694

Marlow LA, Waller J, Wardle J (2007b) Parental attitudes to pre-pubertal HPV vaccination. Vaccine 25: $1945-1952$

Marlow LA, Waller J, Wardle J (2008) Sociodemographic predictors of HPV testing and vaccination acceptability: results from a population representative sample of British women. J Med Screen 15: 91-96

Marlow LA, Forster AS, Wardle J, Waller J (2009a) Mothers' and adolescents' beliefs about risk compensation following HPV vaccination. J Adolesc Health 44: 446-451 
Marlow LA, Waller J, Evans RE, Wardle J (2009b) Predictors of interest in HPV vaccination: A study of British adolescents. Vaccine 27: 2483-2488

Marlow LA, Wardle J, Forster A, Waller J (2009c) Ethnic differences in human papillomavirus awareness and vaccine acceptability. J Epidemiol Community Health 63: 1010-1015

Marlow LA, Wardle J, Waller J (2009d) Attitudes to HPV vaccination among ethnic minority mothers in the UK: an exploratory qualitative study. Hum Vaccin 5: 105-110

Marteau TM, Dormandy E, Michie S (2001) A measure of informed choice. Health Expect 4: 99-108

Morison LA, Cozzolino PJ, Orbell S (2010) Temporal perspective and parental intention to accept the human papillomavirus vaccination for their daughter. $\mathrm{Br}$ J Health Psychol 15: 151 - 165

Moser K, Patnick J, Beral V (2009) Inequalities in reported use of breast and cervical screening in Great Britain: analysis of cross sectional survey data. BMJ 338: b2025

Munoz N, Bosch FX, Castellsague X, Diaz M, de SS, Hammouda D, Shah KV, Meijer CJ (2004) Against which human papillomavirus types shall we vaccinate and screen? The international perspective. Int J Cancer 111: $278-285$

Nazroo JY (2006) Health and social research in multiethnic societies. Routledge: Oxon, UK

NCIN (2009) Cancer Incidence and Survival by Major Ethnic Group, England, 2002 - 2006. National Cancer Intelligence Network: London. Available at http://tinyurl.com/NCINethnicityReport (accessed 12 August 2010)

Noakes K, Yarwood J, Salisbury D (2006) Parental response to the introduction of a vaccine against human papilloma virus. Hum Vaccin 2: $243-248$

ONS (2004) Ethnicity \& Identity: Population size. Available at http:// www.statistics.gov.uk/cci/nugget.asp?id = 455 (accessed 12 August 2010)

Peto J, Gilham C, Fletcher O, Matthews FE (2004) The cervical cancer epidemic that screening has prevented in the UK. Lancet 364: 249-256

Philips Z, Johnson S, Avis M, Whynes DK (2003) Human papillomavirus and the value of screening: young women's knowledge of cervical cancer. Health Educ Res 18: 318-328

Pitts M, Clarke T (2002) Human papillomavirus infections and risks of cervical cancer: what do women know? Health Educ Res 17: 706-714
Quinn M, Babb P, Brock A, Kirby L, Jones J (2001) Cancer trends in England and Wales 1950-1999: Studies on Medical and Population Subjects. The Stationary Office: Norwich, UK

Roberts SA, Brabin L, Stretch R, Baxter D, Elton P, Kitchener H, McCann R (2011) Human papillomavirus vaccination and social inequality: results from a prospective cohort study. Epidemiol Infect 139: 400-405

Rondy M, van Lier A, van de Kassteele J, Rust L, de Melker H (2010) Determinants for HPV vaccine uptake in the Netherlands: A multilevel study. Vaccine 28: 2070-2075

Samad L, Tate AR, Dezateux C, Peckham C, Butler N, Bedford H (2006) Differences in risk factors for partial and no immunisation in the first year of life: prospective cohort study. BMJ 332: 1312-1313

Senior PA, Bhopal R (1994) Ethnicity as a variable in epidemiological research. BMJ 309: $327-330$

Stretch R, Roberts SA, McCann R, Baxter D, Chambers G, Kitchener H, Brabin L (2008) Parental attitudes and information needs in an adolescent HPV vaccination programme. $\mathrm{Br}$ J Cancer 99: 1908-1911

Sturm LA, Mays RM, Zimet GD (2005) Parental beliefs and decision making about child and adolescent immunization: from polio to sexually transmitted infections. J Dev Behav Pediatr 26: $441-452$

Vallely LA, Roberts SA, Kitchener HC, Brabin L (2008) Informing adolescents about human papillomavirus vaccination: what will parents allow? Vaccine 26: 2203-2210

Waller J, Marlow LA, Wardle J (2006) Mothers' attitudes towards preventing cervical cancer through human papillomavirus vaccination: a qualitative study. Cancer Epidemiol Biomarkers Prev 15: 1257-1261

Waller J, McCaffery K, Forrest S, Szarewski A, Cadman L, Wardle J (2003) Awareness of human papillomavirus among women attending a well woman clinic. Sex Transm Infect 79: 320-322

Waller J, McCaffery K, Wardle J (2004) Beliefs about the risk factors for cervical cancer in a British population sample. Prev Med 38: 745-753

Walsh CD, Gera A, Shah M, Sharma A, Powell JE, Wilson S (2008) Public knowledge and attitudes towards Human Papilloma Virus (HPV) vaccination. BMC Public Health 8: 368

Webb R, Richardson J, Esmail A, Pickles A (2004) Uptake for cervical screening by ethnicity and place-of-birth: a population-based crosssectional study. J Public Health 26: 293-296

This work is published under the standard license to publish agreement. After 12 months the work will become freely available and the license terms will switch to a Creative Commons Attribution-NonCommercial-Share Alike 3.0 Unported License. 